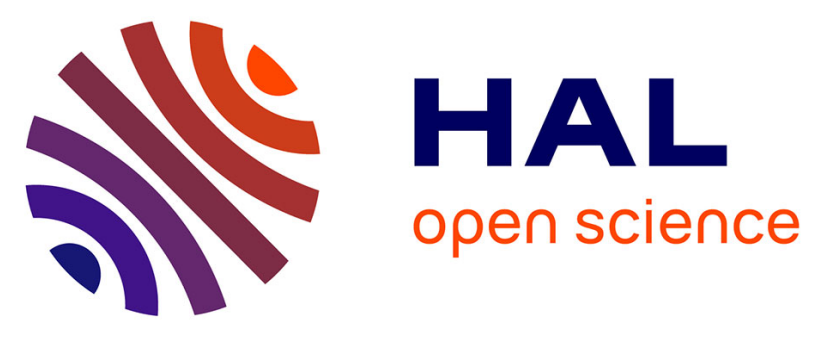

\title{
Water-mediated structuring of bone apatite
}

Yan Wang, Stanislas von Euw, Francisco M. Fernandes, Sophie Cassaignon, Mohamed Selmane, Guillaume Laurent, Gerard Pehau-Arnaudet, Cristina Coelho, Laure Bonhomme-Coury, Marie-Madeleine Giraud-Guille, et al.

\section{- To cite this version:}

Yan Wang, Stanislas von Euw, Francisco M. Fernandes, Sophie Cassaignon, Mohamed Selmane, et al.. Water-mediated structuring of bone apatite. Nature Materials, 2013, 12 (12), pp.1144-1153. 10.1038/NMAT3787 . hal-01289769

\section{HAL Id: hal-01289769 https://hal.science/hal-01289769}

Submitted on 28 Aug 2019

HAL is a multi-disciplinary open access archive for the deposit and dissemination of scientific research documents, whether they are published or not. The documents may come from teaching and research institutions in France or abroad, or from public or private research centers.
L'archive ouverte pluridisciplinaire HAL, est destinée au dépôt et à la diffusion de documents scientifiques de niveau recherche, publiés ou non, émanant des établissements d'enseignement et de recherche français ou étrangers, des laboratoires publics ou privés. 


\title{
Water-mediated structuring of bone apatite
}

\author{
Yan Wang ${ }^{1 \dagger}$, Stanislas Von Euw ${ }^{1 \dagger}$, Francisco M. Fernandes ${ }^{1}$, Sophie Cassaignon ${ }^{1}$, Mohamed Selmane ${ }^{2}$, \\ Guillaume Laurent ${ }^{1}$, Gérard Pehau-Arnaudet ${ }^{3}$, Cristina Coelho ${ }^{2}$, Laure Bonhomme-Coury', \\ Marie-Madeleine Giraud-Guille ${ }^{1}$, Florence Babonneau', Thierry Azaïs ${ }^{1 \star}$ and Nadine Nassif ${ }^{1 \star}$
}

\begin{abstract}
It is well known that organic molecules from the vertebrate extracellular matrix of calcifying tissues are essential in structuring the apatite mineral. Here, we show that water also plays a structuring role. By using solid-state nuclear magnetic resonance, wide-angle X-ray scattering and cryogenic transmission electron microscopy to characterize the structure and organization of crystalline and biomimetic apatite nanoparticles as well as intact bone samples, we demonstrate that water orients apatite crystals through an amorphous calcium phosphate-like layer that coats the crystalline core of bone apatite. This disordered layer is reminiscent of those found around the crystalline core of calcified biominerals in various natural composite materials in vivo. This work provides an extended local model of bone biomineralization.
\end{abstract}

$\longrightarrow$ uestions persist on mechanisms that control bone biomineralization processes $^{1}$. In particular, the nature and functions of the components involved in the formation and organization of apatite crystals in bone remain debatable. Still, it is well known that organic molecules from the extracellular matrix-for example, collagen ${ }^{2}$, proteoglycans ${ }^{3}$ and non-collagenous proteins ${ }^{4}$ - are key components in the mediation of the organization of apatite crystals.

In addition, it has recently been proposed that a distinct mineral domain around the crystalline core of some calcified biominerals exists in different composite materials in vivo (that is, dentin ${ }^{5}$, nacre $^{6}$ and bone $e^{7}$ ) and in vitro (aragonite ${ }^{8}$ and hydroxyapatite ${ }^{9}$ ) as well as in meteoritic materials ${ }^{10}$. The role of this distinct surface mineral domain is, however, not well understood. Previous studies suggest that it is involved in the local increase in concentration and reactivity of ions in bone, such as $\mathrm{Ca}^{2+}, \mathrm{Mg}^{2+}, \mathrm{CO}_{3}{ }^{2-}$ and $\mathrm{HPO}_{4}{ }^{2-}$, which has strong implications for bone crystal formation and resorption ${ }^{11}$. Such a dynamic character of bone remodelling along with the diversity of calcified tissues in vertebrates (such as bone, dentin and enamel) partly explains why the nature of this distinct surface mineral domain in bone remains unclear in the literature. Also, appropriate apatite models are lacking. Indeed, although in vitro synthesis of HA presents enhanced versatility due to different adjustable parameters (such as the nature of calcium phosphate precursors, the presence of water, and temperature), its crystal structure (usually highly crystallized) and chemical composition (slightly substituted) are significantly different from the mineral phase in bone. Such differences also result from the fact that for most of the spectroscopic studies available in the literature, bone samples were often altered and substantially dried.

Here, we show that, as with organic components, water-the third main component in bone-also plays a structuring role by orienting apatite crystals. Structuring water should not be confused with putative structural water molecules incorporated in the lattice structure of the bone crystals ${ }^{12}$. The water-induced orientation of apatite crystals yields an extension to the localized fibrillar model of bone biomineralization ${ }^{13}$, and complements the putative roles proposed in the literature for crystal-surface-bound (as opposed to bulk) water ${ }^{14}$ : as a contributor to the mechanical properties of bone ${ }^{15}$ and as an interfacial agent between collagen and apatite ${ }^{16}$. We also show that structuring water molecules strongly interact with the mineral only when a disordered mineral layer coats the crystalline core of the mineral particles. We provide evidence for this disordered layer on the basis of advanced solid-state nuclear magnetic resonance (ssNMR) experiments, which also support a consensual hypothesis in the literature ${ }^{7}$. We also provide new insights into the structural characteristics of bone mineral. The disordered mineral layer is highly hydrophilic and composed of the divalent ions $\mathrm{Ca}^{2+}, \mathrm{HPO}_{4}{ }^{2-}$ and $\mathrm{CO}_{3}{ }^{2-}$, and water. We identify it as an amorphous calcium phosphate (ACP)-related phase, as previously stated for dentin ${ }^{5}$ and synthetic ${ }^{17}$ apatites. Our results strongly rely on the use of freshly extracted bone kept in its native hydration state, but we complement our study with a variety of bone-derived samples (dry, free of organic matrix) and apatite models (from crystalline to biomimetic particles possessing different morphologies), as well as with ACP particles. On the basis of quantitative and qualitative results, we propose that the oriented stacking of the platelets in water is mediated by the ACP-like layer, whose affinity towards water traps a rigid water layer between adjacent apatite particles.

\section{Water adsorption properties of bone apatite}

To better understand the implication of water molecules in bonebiomineralization events, freshly extracted bone was compared with dry bone samples. To prevent specimen alteration by chemical pre-treatment and avoid artefacts caused by dehydration ${ }^{18}$ (for example, collapse of the collagen network), freshly extracted bone was used without any treatment, and the spectroscopic studies were conducted within two hours after extraction from healthy animals. The dry bone sample was obtained by drying the freshly extracted bone under a laminar flow at room temperature. The impact of the dehydration on bone mineral was investigated through ssNMR. The two-dimensional (2D) ${ }^{1} \mathrm{H}-{ }^{31} \mathrm{P}$ heteronuclear correlation (HetCor) experiment allows a selective enhancement 
of protonated species in close proximity with phosphate ions from the mineral matrix of bone. This sequence is widely used in the literature to study the local environment of ${ }^{31} \mathrm{P}$ and ${ }^{1} \mathrm{H}$ in synthetic and bone apatites ${ }^{19}$, as well as in vitro models ${ }^{20}$. Thus, we conducted similar experiments on both the dry (Fig. 1a, green) and fresh intact bone samples (Fig. 1a, red). We identify two phosphate environments for both samples. For the dry bone sample, two distinct ${ }^{31} \mathrm{P}$ signals on the $2 \mathrm{D}$ spectra exhibit similar chemical shifts $\left(\delta\left({ }^{31} \mathrm{P}\right)=3.2 \mathrm{ppm}\right)$ but different linewidths: the sharp resonance $(\mathrm{LW}=2.2 \mathrm{ppm})$ correlates with hydroxyl anions at $\delta\left({ }^{1} \mathrm{H}\right)=0 \mathrm{ppm}$; the broad ${ }^{31} \mathrm{P}$ signal correlates with a weak ${ }^{1} \mathrm{H}$ resonance spanning from 5 to $15 \mathrm{ppm}$. This latter ${ }^{1} \mathrm{H}$ resonance is commonly assigned to $\mathrm{HPO}_{4}{ }^{2-}$ ions and residual water ${ }^{19}$. The sharper ${ }^{31} \mathrm{P}$ signal is assigned to the $\mathrm{PO}_{4}{ }^{3-}$ ions of the apatitic core whereas it is commonly assumed that the broad ${ }^{31} \mathrm{P}$ corresponds to a disordered phosphate phase at the surface. Noticeably, the 2D spectrum of the dry bone sample is in agreement with previous data obtained for synthetic ${ }^{9}$ and biological apatites ${ }^{5,16,21,22}$. Interestingly, the spectroscopic signature is different for the fresh bone sample. Indeed, the ${ }^{31} \mathrm{P}$ broad signal exhibits a strong correlation with adsorbed-water resonance $\left(\delta\left({ }^{1} \mathrm{H}\right)=4.85 \mathrm{ppm}\right)$. Moreover, the sharper resonance is not modified on dehydration. As only the broad ${ }^{31} \mathrm{P}$ resonance is sensitive to a hydration/dehydration process, this strengthens the hypothesis that these phosphate ions are located near the surface of bone mineral. It seems that because of partial ${ }^{16,21}$ or complete dehydration ${ }^{5,22}$ of the biological apatites studied in the literature through this technique, the selective correlation between the phosphate ions from the broad resonance and the adsorbed water in bone was never pointed out. This can also be explained by the fact that previous studies focused on the evolution of the water signal as a function of the sample dehydration and not on the phosphate counterpart ${ }^{21}$. Such differences in the spectroscopic signature of fresh versus dry samples strengthen the need to focus more attention on the hydration state of biological materials for both the organic ${ }^{18}$ and the mineral matrices.

There is consensus in the literature over the presence of a disordered phosphate phase at the surface (that is, around the core) of biological apatite particles and some synthetic ones. However, because the coexistence of a separate disordered phase along with the apatite particles cannot be excluded, the evidence of the continuity of the two domains needs to be demonstrated. This demonstration is especially pertinent because ACP particles are proposed as precursors for bone mineral in $v i v o^{23}$. We performed a $2 \mathrm{D}{ }^{31} \mathrm{P}$-filtered ${ }^{1} \mathrm{H}-{ }^{1} \mathrm{H}$ exchange spectroscopy (EXSY) experiment (Fig. $1 \mathrm{~b}$ ) to probe a putative magnetization exchange between protons from the disordered and the crystalline domains. Bone mineral protons were selected through a ${ }^{31} \mathrm{P}$ dipolar-based filter to remove the influence of protons from the organic matrix ${ }^{24}$. The exchange peaks between $\mathrm{OH}^{-}, \mathrm{HPO}_{4}{ }^{2-}$ and residual water show unambiguously that the two domains belong to the same nanocrystal in bone. In addition, it proves that only the surface domain of bone mineral is involved in the dehydration process.

Analysing variable-contact-time 2D experiments in terms of cross-polarization dynamics (Supplementary Fig. 1a) revealed a faster cross-polarization process for phosphate from the surface layer relative to that from the apatitic ones, demonstrating that water molecules are strongly adsorbed owing to the rigid nature of the spin system, and showing a richer proton environment in the surface layer.

Interestingly, ${ }^{31} \mathrm{P}$ quantitative magic-angle spinning (MAS) spectra recorded before and after dehydration show that the overall phosphate content and environment in bone mineral is not modified on dehydration (Supplementary Fig. 1b). This is in contrast with previous results obtained with synthetic apatite where this layer was irreversibly altered on drying ${ }^{25}$.

The proportion of the two domains in bone mineral was evaluated thanks to the fitting of the resulting spectra by the line shapes of the two components detected by 2D HetCor experiments 9 . The proportions of surface layer and apatitic core are 45 and $55 \pm 5 \%$, respectively (Fig. 1c and Supplementary Fig. 1b).

To understand the implication of the surface domain in water adsorption, similar ssNMR studies were conducted on uniformly and highly crystalline apatite (HCA) nanoparticles ${ }^{26}$ that do not possess this distinct surface layer (Fig. 1d, green). The dehydrated/hydrated states of the bone sample were mimicked through the use of dry HCA powder and HCA soaked in water, respectively. Significantly, once wetted, HCA does not exhibit any strong water correlation peak in the corresponding ${ }^{1} \mathrm{H}-{ }^{31} \mathrm{P}$ HetCor spectrum (Fig. 1d, red).

All of these results demonstrate that the ability of water molecules to strongly adsorb onto apatite minerals depends directly on the existence of a highly hydrophilic surface layer.

\section{The mineral nature of the surface layer}

The structural characteristics of the disordered layer remain unclear in the literature, which has led to the use of different terminologies to define it. To better understand the mineral nature of the surface domain, fresh intact bone was compared with biomimetic powders, namely carbonated hydroxyapatite (CHA) and CHA-simulated body fluid (SBF). Synthetic CHA was identified as biomimetic in a previous study ${ }^{27}$ (see HA-2 in ref. 26), and CHA-SBF was precipitated directly from a SBF, a serum-like solution ${ }^{28}$. Both models possess similar structural characteristics to those found in bone as seen by X-ray diffraction (crystallinity) and standard transmission electron microscopy (TEM) observations of particles dispersed in ethanol (size and morphology; Supplementary Fig. 2a-c).

To exclude the effects of the presence of phosphorylated organic molecules that could potentially be detected in the previous 2D NMR experiments on bone samples, 2D ${ }^{1} \mathrm{H}-{ }^{31} \mathrm{P}$ HetCor experiments were performed on wet and dry biomimetic apatites as performed for bone. For both, similar observations on hydration are observed (Supplementary Fig. 3a,b, red versus green). Similar proportions of the apatitic core and the surface mineral layer are also found (Supplementary Fig. 3c,d). These show that a potential contribution of some organic molecules, including phosphorylated species, from the organic matrix ${ }^{29}$ in the ${ }^{1} \mathrm{H}-{ }^{31} \mathrm{P}$ HetCor spectra of bone seems unlikely, confirming the mineral nature of this surface layer in bone.

The specific adsorption of water seems to be mediated by the nature of the particles' surface. However, this difference in behaviour may also be induced by the thinner thickness of the 
CHA and CHA-SBF platelets compared with that of HCA nanorods ( $\sim 2-8$ versus $\sim 30 \mathrm{~nm}$, respectively). To exclude this hypothesis, experiments were also performed on apatite platelets that do not possess an ACP layer at their surface and for which the thickness is in the same range as that found in bone nanocrystals. For this purpose, $\mathrm{CHA}$ and $\mathrm{CHA}-\mathrm{SBF}$ particles were submitted to either a thermal $\left(200^{\circ} \mathrm{C}\right.$; CHA-200) or chemical (alkaline solution; $\mathrm{CHA}-\mathrm{NaOH}$ and $\mathrm{CHA}-\mathrm{SBF}-\mathrm{NaOH}$ ) treatment (Supplementary Methods). According to the ${ }^{31} \mathrm{P}$-filtered ${ }^{1} \mathrm{H}$ NMR spectra for wet samples after such treatments, the water adsorption onto the ACP layer is efficiently reduced for all of the samples to $\sim 80$ and $\sim 90 \%$ for $\mathrm{CHA}-200$ and $\mathrm{CHA}-\mathrm{NaOH}$, respectively, and to $\sim 65 \%$ for $\mathrm{CHA}-\mathrm{SBF}-\mathrm{NaOH}$ (Supplementary Fig. 4). We also find that, as with HCA, water is not adsorbed significantly at the surface of the treated particles. We can thus safely conclude that this difference in behaviour detected by NMR on exposure to water depends only on the nature of the surface (crystalline or not) of the apatite particles.

To probe the crystalline or amorphous nature of the surface mineral layer, similar ssNMR experiments were performed on synthetic amorphous calcium phosphate (ACP; Supplementary Methods). The ${ }^{31} \mathrm{P}$ NMR spectrum of dry ACP consists of a single resonance exhibiting a Gaussian shape characteristic of the amorphous nature of the material (Fig. 2a). This signal is similar in terms of position and linewidth to the ${ }^{31} \mathrm{P}$ broad components detected through the HetCor experiments of bone (Fig. 2a). Moreover, the $2 \mathrm{D}^{1} \mathrm{H}-{ }^{31} \mathrm{P}$ HetCor experiments recorded for dry and $\mathrm{H}_{2} \mathrm{O}$-wetted ACP powder (Fig. 2b, green versus red, respectively) led to a behaviour of the surface layer of bone mineral on hydration that is similar. This result provides evidence that the surface mineral layer of bone apatite is related to an amorphous calcium phosphate phase. A similar conclusion can be drawn for biomimetic samples CHA and CHA-SBF (Supplementary Fig. 5). This is in contrast with previous results obtained for synthetic apatites, where the 'disordered surface'/'structured hydrated layer' was proposed to be a phase related to either that of octacalcium phosphate ${ }^{9}$ or dicalcium phosphate dihydrate ${ }^{25}$. The conclusion is, however, in agreement with statements made for dentin ${ }^{5}$.

The direct observation of this ACP-like layer by TEM could not be evidenced unambiguously in extracted bone particles ${ }^{27}$. Yet it seems easier with synthetic apatites exhibiting also 'nonapatitic' surfaces ${ }^{30,31}$. Moreover, TEM observation of intact bone is technically demanding and requires pre-treatment of the native materials ${ }^{32-34}$. It is thus difficult to draw conclusions. Nevertheless, it should be noted that the presence of an ACP layer cannot be ruled out from previous high-resolution TEM (HRTEM) observations performed on woven bone ${ }^{35}$ and dentin ${ }^{36}$. According to the mineral structural similarities, observations were performed here on $\mathrm{CHA}$ instead of bone (Supplementary Fig. 6a-a'). Despite the high sensitivity of biomimetic samples towards the electron beam, the presence of the outer amorphous layer was nonetheless revealed by HRTEM observations.

Taken together, these results strongly suggest that the structure of bone mineral particles consists of a core-layer organization where the apatitic core is covered by a highly hydrophilic ACP-like layer.

\section{Ionic composition of the ACP-like layer}

To probe a possible chemical exchange between protons from the ACP-like layer and the strongly adsorbed water, a $\mathrm{D}_{2} \mathrm{O}$ soaked bone sample was studied by ${ }^{1} \mathrm{H}-{ }^{31} \mathrm{P}$ HetCor ssNMR spectroscopy. The addition of $\mathrm{D}_{2} \mathrm{O}$ to the fresh bone sample leads to the disappearance of the correlation peak at $\delta\left({ }^{1} \mathrm{H}\right)=4.85 \mathrm{ppm}$ (Fig. 3a). Thus, water molecules adsorbed at the apatite surface in bone remain accessible to a chemical exchange through $\mathrm{D}_{2} \mathrm{O}$. Moreover, the broad resonance $\left(\delta\left({ }^{1} \mathrm{H}\right)=5-15 \mathrm{ppm}\right)$ is now absent, indicating that water molecules are involved in a proton chemical exchange with the mineral surface species, and thus confirming their nature as $\mathrm{HPO}_{4}{ }^{2-}$ ions and residual $\mathrm{H}_{2} \mathrm{O}$. The ${ }^{1} \mathrm{H}$ chemical shifts of $\mathrm{HPO}_{4}{ }^{2-}$ groups and residual water are consistent with previously calculated data on various calcium phosphate phases, demonstrating that the ${ }^{1} \mathrm{H}$ chemical shift of such species increases with increasing $\mathrm{H}$-bond strength ${ }^{37}$. It is worth mentioning that such $\mathrm{D}_{2} \mathrm{O} / \mathrm{H}_{2} \mathrm{O}$ chemical exchange is also observed for biomimetic apatites (Supplementary Fig. 6b-d).

The ionic composition of the ACP-like layer was then studied through selective ${ }^{13} \mathrm{C}$ and ${ }^{43} \mathrm{Ca}$ labelling on $\mathrm{CHA}$ because of the versatility of its synthesis ${ }^{27}$. As it has been postulated that the formation of a surface mineral layer is driven by the presence of $\mathrm{CO}_{3}{ }^{2-}$ as substituting ions in the apatite structure ${ }^{25,38}$, we investigated their presence through ${ }^{1} \mathrm{H}-{ }^{13} \mathrm{C}$ HetCor experiments (Fig. 3b, green) on both dry and water-soaked $100 \%{ }^{13} \mathrm{C}$-labelled CHA $\left({ }^{13} \mathrm{C}^{*}-\mathrm{CHA}\right)$. The carbonate ions from the apatitic core were identified by the specific correlation with hydroxyl ions 
$\left(\delta\left({ }^{1} \mathrm{H}\right)=0 \mathrm{ppm}\right)$. The proximity of some $\mathrm{CO}_{3}{ }^{2-}$ ions with species from the ACP-like layer was evidenced by the correlation with the weak and broad resonance in the dry state that merges into a sharp signal in the wetted state, as observed for ${ }^{1} \mathrm{H}-{ }^{31} \mathrm{P}$ HetCor experiments. This result demonstrates that a substantial number of carbonate ions are also present in the ACP layer (Fig. 3b, red).

The investigation of the composition was pursued through ${ }^{43} \mathrm{Ca}$ NMR of a $60 \%{ }^{43} \mathrm{Ca}$-enriched $\mathrm{CHA}$ sample $\left({ }^{43} \mathrm{Ca}^{*}-\mathrm{CHA}\right)$. To investigate the ${ }^{43} \mathrm{Ca}-{ }^{1} \mathrm{H}$ spatial proximity, we used ${ }^{1} \mathrm{H}-$ $\left\{{ }^{43} \mathrm{Ca}\right\}$ transfer of population in double resonance (TRAPDOR) experiments ${ }^{39}$. This experiment uses ${ }^{43} \mathrm{Ca}-{ }^{1} \mathrm{H}$ dipole interaction leading to the dephasing of ${ }^{1} \mathrm{H}$ resonance close to ${ }^{43} \mathrm{Ca}$. The ${ }^{1} \mathrm{H}-\left\{{ }^{43} \mathrm{Ca}\right\}$ TRAPDOR difference spectrum (Fig. 3c) of dry ${ }^{43} \mathrm{Ca}^{*}-$ CHA exhibits the characteristic resonance of apatitic hydroxyls $(0 \mathrm{ppm})$ as well as a broader signal that corresponds to residual $\mathrm{H}_{2} \mathrm{O}$ according to its chemical shifts $(5.2 \mathrm{ppm})$. The deshielded resonances of the proton signal assigned to $\mathrm{HPO}_{4}{ }^{2-}$ (up to $15 \mathrm{ppm}$ ) are not detected in this experiment, probably owing to a weak intensity combined with a short $\mathrm{T}_{2}\left({ }^{1} \mathrm{H}\right)$. Note that the sharp peaks corresponding to impurities (2-4 ppm) are not submitted to a TRAPDOR effect and thus are not dipolarily coupled to ${ }^{43} \mathrm{Ca}$.

In summary, the distinct highly hydrophilic domain that is located at the surface of bone nanocrystals consists of an ACPrelated phase. This ACP-like layer is composed of $\mathrm{HPO}_{4}{ }^{2-}$, and certainly of $\mathrm{CO}_{3}{ }^{2-}$ and $\mathrm{Ca}^{2+}$. The result does not exclude that other ions, such as $\mathrm{Na}^{+}, \mathrm{Cl}^{-}$and $\mathrm{Mg}^{2+}$, may also be present in the layer, as previously proposed in the literature ${ }^{11}$. On the basis of spectroscopic studies, these same ions were proposed to be part of the surface layer of synthetic HA, where a dicalcium phosphate dihydrate-like phase was suggested ${ }^{25}$. All protons from the ACP-like layer are in a dynamical exchange, which suggests that a waterinduced network is present within the amorphous mineral layer.
In contrast to previous studies performed at the collagen/mineral interface $e^{16,40}$, this water-induced network seems to be inherent to the particle and, more precisely, to the ACP-like layer. However, our results do not exclude the presence of a water hydration shell around the particles. Noticeably, ACP particles are described as highly transient, especially in the presence of water ${ }^{41}$, whereas the ACP-like layer at the surface of bone mineral remains stable during the different time courses of the experiments performed in our study. It should be noted that our results do not settle the debate about the nature of the first-formed mineral phase in vivo ${ }^{23,42}$.

\section{Role of the water-induced network}

To further understand the role played by the water-induced network, wide-angle X-ray scattering (WAXS) by transmission mode was also performed on CHA soaked in water and on dry CHA powders (Fig. 4a) inserted in capillary tubes (Supplementary Methods). As the background signal is exacerbated in the presence of water (Supplementary Fig. 7a), 1D radial averages of the WAXS patterns are shown (including the baseline correction).

The dry and wetted samples exhibit the characteristic diffraction peaks-(002) and merged (211), (112), (300), (202) reflections-of carbonated apatite. However, when hydrated, there is a noticeable augmentation of the intensity for the (002) reflection relative to the merged reflections, whereas the linewidth of the reflections remains unchanged. Interestingly, the ratio of the intensities of the merged reflections $\left(2 \theta=31.9^{\circ}\right)$ to $(002)\left(2 \theta=25.9^{\circ}\right)$ decreases in the presence of water (1.87 versus 1.59$)$. The fitting of the (002), (211), (112), (300), (202) reflections by five line shapes (by varying intensities but keeping constant the positions and linewidths) confirmed this trend, as the (002) to (300) intensity ratio increases in the presence of water $(+35 \%$; Supplementary Fig. $7 \mathrm{~b})$.

Similar observations were obtained for CHA-SBF (2.88 versus 2.36; Fig. 4b), whereas the intensities remained unchanged for
HCA (Fig. 4c). Owing to the difference in morphology between CHA/CHA-SBF and HCA (nanoplatelets versus nanorods, respectively), same WAXS investigations were performed on CHA apatite platelets after selective removal of the ACP-like layer at their surface through thermal treatment, namely CHA-200. The presence of water also does not influence the relative intensities of CHA-200 reflections as observed for HCA (Fig. 4d). The difference in behaviour between CHA/CHA-SBF and CHA-200 excludes a possible orientation of the particles through a capillary confinement effect. Nevertheless, it is worth mentioning that, in vivo, the extracellular fluid continuously circulates throughout the bone tissue inside narrow inter- and intrafibrillar spaces, where a related phenomenon is likely to occur.

All of the results suggest that water induces the orientation of the biomimetic platelets in the $c$-axis direction through the ACPlike layer. Although it is commonly accepted that the alignment of apatite crystals in bone along the $c$-axis is mediated by the organic components, this is unlikely to occur here because our WAXS experiments were performed on samples free of any organic fraction.

To support our WAXS diffraction data further, we carried out cryogenic TEM (cryoTEM) observations of apatite samples 
exhibiting variable amounts of the ACP-like layer. This technique allows for sample observation while preserving the hydration of the ACP-like layer. Observations of a water suspension of either CHA or CHA-SBF powders clearly show a preferential longitudinal orientation (Fig. 5a-c, single-headed dotted white arrow; up to $\sim 500 \mathrm{~nm}$ ) and lateral packing (up to $\sim 200 \mathrm{~nm}$; Fig. 5a-c, double-headed dotted white arrow) of the apatite crystals. These platelets are seen edge-on whereas those lying flat are seen randomly distributed. A closer look at the cryoTEM images indicates some degree of mismatch in the CHA packing (Fig. 5b and Supplementary Fig. 8a). The way the CHA-SBF particles aggregate seems more regular, exhibiting boundaries that are hardly distinguishable in the longitudinal direction (Fig. $5 \mathrm{c}$ and Supplementary Fig. 8b). This may be due to the crystal-size polydispersity of the CHA particles (Supplementary Fig. 2b) as compared with CHA-SBF, which seem monodispersed in size (Supplementary Fig. 2c). In contrast, HCA nanorods exhibit a random in-plane distribution (Supplementary Fig. 8c). It is likely that the morphology of platelets of CHA and CHA-SBF crystals could favour the oriented stacking ${ }^{43}$ in comparison with HCA nanorods. However, cryoTEM observations performed on CHA200, CHA-NaOH and CHA-SBF-NaOH did not reveal any oriented arrangements; instead, only a few small aggregates were observed locally (Fig. 5d and Supplementary Fig. 8d,e).

To strengthen the involvement of water in this phenomenon, TEM observations were performed on biomimetic samples (CHA and CHA-SBF) dispersed in water (Fig. 5e and Supplementary Fig. $8 \mathrm{f}$, respectively), instead of in ethanol as in the standard preparation procedure (Supplementary Fig. 2b,c). A few aggregates are still observed when prepared in water, meaning that the disruption as a result of the loss of water was slightly avoided (Fig. 5e, white arrow). They are also smaller in size compared with those observed by cryoTEM $(\sim 100 \mathrm{~nm})$. Instead, if they aggregate, particles exhibit a random distribution when prepared in ethanol. The absence of a preferred orientation of the platelets that lay parallel to the grid was further confirmed by electron tomography (see Supplementary Movie). These observations suggest that aggregates on the grid are reminiscent of the assemblies occurring in water. Hence, in addition to the ACP-like layer, water is also essential for the long-range orientation of the platelets.

Unexpectedly, this organization of the HA platelets is reminiscent of that found in bone (Fig. 5f), despite the sample being free of an organic fraction. To assess the putative occurrence of this phenomenon in vivo, cryoTEM observations were also conducted on extracted bone samples. Among the different techniques (chemical or biochemical) proposed in the literature to extract the mineral particles from the organic matrix, we selected the procedure that both preserves the ACP-like layer at the surface of the particles more efficiently (Supplementary Fig. 9) and allows complete removal of the organic matrix ${ }^{44}$. Standard TEM observations of the extracted particles are in agreement with previously reported results $^{44}$, showing well-dispersed irregular platelets of $\sim 50 \mathrm{~nm}$ in size (Fig. $5 \mathrm{~g}$ ). In contrast, cryoTEM experiments performed in water show oriented arrangements similar to those observed for CHA and CHA-SBF particles (Fig. 5h). Nevertheless, the size of the aggregates seems slightly smaller $(\sim 50 \mathrm{~nm}$ in size for the lateral packing and up to $\sim 300 \mathrm{~nm}$ in size for the longitudinal packing). This discrepancy in behaviour may be due to the deproteination procedure partially affecting the ACP-like layer of some of the particles, even if the ssNMR signal shows that it is mostly preserved (Supplementary Fig. 9). It should be noted that thicker particles may be composed of several crystals superimposed or may be remnants of some that were not completely dispersed. The average distance between platelets seen edge-on (that may include the water layer and the ACP layer) is around $2 \mathrm{~nm}$ thick. This observation is coherent with those from HRTEM measurements of apatite in woven bone $e^{35}$ and in dentin ${ }^{36}$, where this gap has been assigned to collagen despite the fact that the latter contains only a few per cent of organic matrix.

In summary, the related results suggest that water may play a role in organizing locally apatite crystals in bone. The ACPlike layer of bone mineral is a key structural parameter for the observed oriented aggregation. These results emphasize the need for a periodic scaffold to control the spatial distribution of apatite crystals, which is provided by the $3 \mathrm{D}$ fibrillar collagen matrix in vivo ${ }^{33}$.

\section{Assembly of ordered apatite platelets}

To understand the oriented assembly of biomimetic and biological apatite platelets, we investigated the nature of the interface between the ACP-like layer and water.

We measured the global charge of the apatite surface (slipping plane) through $\xi$ potential measurements. As for cryoTEM observations, it is worth mentioning that this study is performed in dilute dispersion without the bone organic scaffold. The other main deviation from in vivo conditions is the absence of a buffered physiological medium. However, these conditions provide some insight into the particles' surface properties and their buffer capacity, as previously proposed on synthetic HA, where the presence of a disordered layer was undetermined ${ }^{45}$. After immersion in deionized water $(\mathrm{pH}=5.5)$ and mild ultrasonic dispersion of CHA, CHA-200, CHA-SBF platelets and HCA nanorods, the $\xi$ potential and the suspension $\mathrm{pH}$ were followed as a function of the time elapsed after ultrasonication (20, 40 and $120 \mathrm{~min}$ ). The most noticeable feature is the very low surface charge determined for all samples. CHA and CHA-200 exhibit $\xi$ potentials close to 5 and $3 \mathrm{mV}$, respectively, throughout the different measured times. CHA-SBF and HCA exhibit, however, a slightly negative $\xi$ potential of around $-2 \mathrm{mV}$. These observations indicate that the potential at the slipping plane of the hydrated layer around the particle is close to that of bulk water, which should exclude any possibility of a self-assembly mechanism based on electrostatic interactions between apatite particles for all of the samples. To unveil the exchanges between the dispersed particles and water, we conducted $\mathrm{pH}$ determinations on the apatite dispersions. For all samples where the amorphous layer was present (that is, CHA, CHA-SBF and CHA-200 to a lesser extent), the $\mathrm{pH}$ rapidly rose from 5.5 to around 8 followed by stabilization at $60 \mathrm{~min}$ at a physiological $\mathrm{pH}$ of $7.4 \pm 0.2$. Conversely, HCA, where no disordered layer is present, did not produce such a pronounced $\mathrm{pH}$ variation, stabilizing the $\mathrm{pH}$ of the suspension at around $\mathrm{pH}$. These results suggest that the ACP-like layer may be involved in the amphoteric properties and buffer capacity. Moreover, it provides a favourable chemical environment for ion exchange, allowing the regulation of the medium acidity at physiological conditions, as previously proposed $^{25}$. The lack of strong electrostatic forces between the apatite platelets, along with the absence of an organic fraction acting as a steric stabilizer, rules out two of the main colloidal stabilization mechanisms (that is, electrostatic and steric) that could explain the observed degree of order ${ }^{43}$. Thus, van der Waals attractive forces mediated by a water layer tightly bound to the particles' surface may drive the interaction between the platelets.

To confirm this mechanistic proposition, two techniques were used. Thermogravimetric analysis was first performed on the samples to determine their water content ${ }^{46}$. Thermogravimetric analysis data (Fig. 6a) show the highest water content for CHASBF (13 wt \%), followed by CHA (7 wt \%) and HCA (3 wt \%), as measured from the samples' weight variation $\left(25-400^{\circ} \mathrm{C}\right)$. To gain further detail about this observation, dynamic water vapour sorption studies were then conducted (Fig. 6b-d). This technique allows one to ascertain the adsorption capacity as well as revealing the affinity between water and the mineral surface. The ensemble of 
these results is corroborated by water sorption isotherms (Fig. 6b), where CHA-SBF presents the highest water adsorption capacity $\left(0.55 \mathrm{~g} \mathrm{~g}^{-1}\right)$, followed by HCA $\left(0.37 \mathrm{~g} \mathrm{~g}^{-1}\right)$, CHA $\left(0.21 \mathrm{~g} \mathrm{~g}^{-1}\right)$ and CHA-200 $\left(0.16 \mathrm{~g} \mathrm{~g}^{-1}\right)$ at $95 \%$ relative humidity. The maximum water uptake capacity doesn't seem to completely support the results observed in cryoTEM. However, when fitting the initial segment of the different adsorption isotherms to the linearized Brunauer-Emmett-Teller model, it is meaningful to determine two critical elements, that is, the $C$ parameter (Fig. 6c) and the monolayer capacity (Fig. 6d) so as to inspect the interface between adsorbed water and the particle bare surface ${ }^{47}$. On the one hand, the $C$ parameter is an empirical measure related to the heat of adsorption of the first layer; it can roughly describe how rigidly water is bound to the surface of the apatite particles. On the other hand, the monolayer capacity describes the amount of water that should be stripped out of the surface in order for two particles to stick together without a hydrated layer in between. As can be seen from the values reported in Fig. $6 c$, the highest values for the $C$ parameter are for CHA (21) and CHA-200 (17), followed by CHA-SBF (12) and HCA (3.8). It is worth noting that the $C$ parameter values reported for CHA, CHA-200 and CHA-SBF are at least three times higher than the value reported for HCA. These values are in good agreement with the tendency for the samples to exhibit ordered assemblies in the presence of water. The comparatively low value of the $C$ parameter of CHA-SBF seems to be counterbalanced by the extensive water monolayer capacity exhibited by this sample of around $2.7 \mathrm{mmol}$ per gram of apatite sample, which is almost double that of the HCA sample. The combination of these two parameters can qualitatively explain how much resistance the hydrated layer around an apatite particle provides to oppose the aggregation, and thus how likely it is for a rigid water layer to be trapped between adjacent particles (Fig. 6e) when these are pulled together by van der Waals forces. These results are in agreement with previous $\mathrm{H}_{2} \mathrm{O}$ vapour adsorption microcalorimetry and $a b$ initio calculations, although the degree of crystallinity of such apatite remains unclear ${ }^{48}$. Moreover, they strengthen the results obtained by means of variable-contact-time $2 \mathrm{D}$ experiments in terms of cross-polarization dynamics conducted in bone samples where the role of the amorphous layer has been demonstrated.

If the same rationale is applied to the biological tissue, we propose that the structuring water network in bone favours locally the stacking and orientation of the apatite platelets. This is specifically meaningful where apatite platelets are not directly in contact with the surface of the collagen fibrils, that is, inside the volume delimitated by the contiguous 'holes' as well as in the relatively large extrafibrillar spaces of the matrix (20-30\%; ref. 49), where collagen fibrils do not co-align. This yields an extension to the localized fibrillar model ${ }^{13}$. In addition to the previously proposed non-fibrillar organic matrix ${ }^{2,50}$, water may also act as a continuous medium between the particles and consequently enhance its mechanical properties ${ }^{15,51}$.

\section{Outlook}

Besides its probable biochemical function, the surface ACP-like layer coating the crystalline core of bone apatite would allow the binding of a significant amount of water molecules that mediate the orientation of the apatite crystals.

Up to now, a great deal of attention has focused on the role of organic components in the alignment of the bone crystals. We have demonstrated that water may also be involved locally. Water is the third main component of bone, and it may play various roles that are reflected by the different types of water (for example, rigid or mobile) found in vivo ${ }^{52}$. The importance of hydration, well known for the three-dimensional structure and activity of proteins ${ }^{53}$, can be extended to the mineral matrix.
The fact that a disordered mineral layer is found around other calcified biominerals in vivo and in vitro can be a paragon for understanding the generation of significantly enhanced mechanical properties in natural and synthetic composite materials. This is particularly meaningful in natural materials that contain much less organic component than bone (such as dentin and nacre). Furthermore, by means of mimics of the biological structure of bone, this work provides a sophisticated model for future studies aimed at biomimetic bone mineralization.

\section{Methods}

Full details of the apatite synthesis and sample characterization techniques used are presented in the Supplementary Information.

Received 19 July 2012; accepted 18 September 2013; published online 10 November 2013

\section{References}

1. Boskey, A. L. Biomineralization: Conflicts, challenges, and opportunities. J. Cell. Biochem. 72, 83-91 (1998).

2. Landis, W. J., Song, M. J., Leith, A., McEwen, L. \& McEwen, B. F. Mineral and organic matrix interaction in normally calcifying tendon visualized in 3 dimensions by high-voltage electron-microscopic tomography and graphic image-reconstruction. J. Struct. Biol. 110, 39-54 (1993).

3. Wise, E. R. et al. The organic-mineral interface in bone is predominantly polysaccharide. Chem. Mater. 19, 5055-5057 (2007).

4. He, G., Dahl, T., Veis, A. \& George, A. Nucleation of apatite crystals in vitro by self-assembled dentin matrix protein 1. Nature Mater. 2, 552-558 (2003).

5. Huang, S-J., Tsai, Y-L., Lee, Y-L., Lin, C-P. \& Chan, J. C. C. Structural model of rat dentin revisited. Chem. Mater. 21, 2583-2585 (2009).

6. Nassif, N. et al. Amorphous layer around aragonite platelets in nacre. Proc. Natl Acad. Sci. USA 102, 12653-12655 (2005).

7. Wu, Y. et al. Nuclear magnetic resonance spin-spin relaxation of the crystals of bone, dental enamel, and synthetic hydroxyapatites. J. Bone Miner. Res. 17, 472-480 (2002).

8. Nassif, N. et al. Synthesis of stable aragonite superstructures by a biomimetic crystallization pathway. Angew. Chem. Int. Ed. 44, 6004-6009 (2005).

9. Jäger, C., Welzel, T., Meyer-Zaika, W. \& Epple, M. A solid-state NMR investigation of the structure of nanocrystalline hydroxyapatite. Magn. Reson. Chem. 44, 573-580 (2006).

10. Benzerara, K., Menguy, N., Guyot, F., Dominici, C. \& Gillet, P. Nanobacteria-like calcite single crystals at the surface of the Tataouine meteorite. Proc. Natl Acad. Sci. USA 100, 7438-7442 (2003).

11. Glimcher, M. J. in Medical Mineralogy and Geochemistry Vol. 64 (eds Sahai, N. \& Schoonen, M. A. A.) 223-282 (Reviews in Mineralogy \& Geochemistry, 2006).

12. Yoder, C. H., Pasteris, J. D., Worcester, K. N. \& Schermerhorn, D. V. Structural water in carbonated hydroxylapatite and fluorapatite: Confirmation by solid state H-2 NMR. Calcif. Tissue Int. 90, 60-67 (2012).

13. Hodge, A. \& Petruska, J. in Aspects of Protein Structure (ed. Ramachandran, G.) 289-300 (Academic, 1963).

14. Neuman, W. \& Bareham, B. Further studies on the nature of fluid compartmentalization in chick calvaria. Calcif. Tissue Int. 17, 249-255 (1975).

15. Cowin, S. C. Bone poroelasticity. J. Biomech. 32, 217-238 (1999).

16. Wilson, E. E. et al. Highly ordered interstitial water observed in bone by nuclear magnetic resonance. J. Bone Miner. Res. 20, 625-634 (2005).

17. Jäger, C., Maltsev, S. \& Karrasch, A. Progress of structural elucidation of amorphous calcium phosphate (ACP) and hydroxyapatite (HAp): Disorder and surfaces as seen by solid state NMR. Key Eng. Mater. 309-311, 69-72 (2006).

18. Zhu, P. et al. Time-resolved dehydration-induced structural changes in an intact bovine cortical bone revealed by solid-state NMR spectroscopy. J. Am. Chem. Soc. 131, 17064-17065 (2009).

19. Kolodziejski, W. in New Techniques in Solid-State NMR Vol. 246 (ed. Klinowski, J.) 235-270 (Springer, 2004).

20. Silvent, J. et al. Collagen osteoid-like model allows kinetic gene expression studies of non-collagenous proteins in relation with mineral development to understand bone biomineralization. PLOS ONE 8, e57344 (2013).

21. Cho, G., Wu, Y. \& Ackerman, J. L. Detection of hydroxyl ions in bone mineral by solid-state NMR spectroscopy. Science 300, 1123-1127 (2003).

22. Maltsev, S., Duer, M. J., Murray, R. C. \& Jaeger, C. A solid-state NMR comparison of the mineral structure in bone from diseased joints in the horse. J. Mater. Sci. 42, 8804-8810 (2007).

23. Mahamid, J. et al. Mapping amorphous calcium phosphate transformation into crystalline mineral from the cell to the bone in zebrafish fin rays. Proc. Natl Acad. Sci. USA 107, 6316-6321 (2010). 
24. Folliet, N. et al. Investigation of the interface in silica-encapsulated liposomes by combining solid state NMR and first principles calculations. J. Am. Chem. Soc. 133, 16815-16827 (2011).

25. Rey, C., Combes, C., Drouet, C., Sfihi, H. \& Barroug, A. Physico-chemical properties of nanocrystalline apatites: Implications for biominerals and biomaterials. Mater. Sci. Eng, C 27, 198-205 (2007).

26. Takemoto, S. et al. Selective protein adsorption and blood compatibility of hydroxy-carbonate apatites. J. Biomed. Mater. Res. A 69A, 544-551 (2004).

27. Nassif, N. et al. In vivo inspired conditions to synthesize biomimetic hydroxyapatite. Chem. Mater. 22, 3653-3663 (2010).

28. Rhee, S. H. \& Tanaka, J. Hydroxyapatite formation on cellulose cloth induced by citric acid. J. Mater. Sci. 11, 449-452 (2000).

29. Hu, Y-Y., Rawal, A. \& Schmidt-Rohr, K. Strongly bound citrate stabilizes the apatite nanocrystals in bone. Proc. Natl Acad. Sci. USA 107, 22425-22429 (2010)

30. Bertinetti, L. et al. Surface structure, hydration, and cationic sites of nanohydroxyapatite: UHR-TEM, IR, and microgravimetric studies. J. Phys. Chem. C 111, 4027-4035 (2007).

31. Ren, F. Z., Leng, Y., Ding, Y. H. \& Wang, K. F. Hydrothermal growth of biomimetic carbonated apatite nanoparticles with tunable size, morphology and ultrastructure. CrystEngComm 15, 2137-2146 (2013).

32. Landis, W. J., Paine, M. C. \& Glimcher, M. J. Electron-microscopic observations of bone tissue prepared anhydrously in organic-solvents. J. Ultrastruct. Res. 59, 1-30 (1977).

33. Wang, Y. et al. The predominant role of collagen in the nucleation, growth, structure and orientation of bone apatite. Nature Mater. 11, 724-733 (2012).

34. Weiner, S., Traub, W. \& Wagner, H. D. Lamellar bone: Structure-function relations. J. Struct. Biol. 126, 241-255 (1999).

35. Su, X., Sun, K., Cui, F. Z. \& Landis, W. J. Organization of apatite crystals in human woven bone. Bone 32, 150-162 (2003)

36. Beniash, E. Biominerals-hierarchical nanocomposites: the example of bone. WIRes Nanomed. Nanobiotech. 3, 47-69 (2011).

37. Gervais, C. et al. First principles NMR calculations of phenylphosphinic acid $\mathrm{C} 6 \mathrm{H} 5 \mathrm{HPO}(\mathrm{OH})$ : Assignments, orientation of tensors by local field experiments and effect of molecular motion. J. Magn. Reson. 187, 131-140 (2007).

38. Dorozhkin, S. V. Nanodimensional and nanocrystalline apatites and other calcium orthophosphates in biomedical engineering, biology and medicine. Materials 2, 1975-2045 (2009).

39. Grey, C. P. \& Vega, A. J. Determination of the quadrupole coupling-constant of the invisible aluminum spins in zeolite $\mathrm{HY}$ with ${ }^{1} \mathrm{H} /{ }^{27} \mathrm{Al}$ TRAPDOR NMR. J. Am. Chem. Soc. 117, 8232-8242 (1995).

40. Rai, R. K. \& Sinha, N. Dehydration-induced structural changes in the collagen-hydroxyapatite interface in bone by high-resolution solid-state NMR spectroscopy. J. Phys. Chem. C 115, 14219-14227 (2011).

41. Combes, C. \& Rey, C. Amorphous calcium phosphates: Synthesis, properties and uses in biomaterials. Acta Biomater. 6, 3362-3378 (2010).

42. Rey, C., Combes, C., Drouet, C. \& Glimcher, M. J. Bone mineral: update on chemical composition and structure. Osteoporos. Int. 20, 1013-1021 (2009).

43. Onsager, L. The effects of shape on the interaction of colloidal particles. Ann. New York Acad. Sci. 51, 627-659 (1949).

44. Weiner, S. \& Price, P. A. Disaggregation of bone into crystals. Calcif. Tissue Int. 39, 365-375 (1986).

45. Smiciklas, I. D., Milonjic, S. K., Pfendt, P. \& Raicevic, S. The point of zero charge and sorption of cadmium (II) and strontium (II) ions on synthetic hydroxyapatite. Sep. Purif. Technol. 18, 185-194 (2000).
46. Kanazawa, T., Umegaki, T. \& Uchiyama, N. Thermal crystallization of amorphous calcium-phosphate to alpha-tricalcium phosphate. J. Chem. Technol. Biotechnol. 32, 399-406 (1982).

47. Rouquerol, F., Rouquerol, J. \& Sing, K. Adsorption by Powders and Porous Solids (Academic, 1999).

48. Bolis, V. et al. Coordination chemistry of Ca sites at the surface of nanosized hydroxyapatite: interaction with $\mathrm{H}_{2} \mathrm{O}$ and CO. Phil. Trans. R. Soc. A 370, 1313-1336 (2012)

49. Frasca, P., Harper, R. A. \& Katz, J. L. Mineral and collagen fiber orientation in human secondary osteons. J. Dent. Res. 57, 526-533 (1978).

50. Fantner, G. E. et al. Sacrificial bonds and hidden length dissipate energy as mineralized fibrils separate during bone fracture. Nature Mater. 4, 612-616 (2005).

51. Gupta, H.S. et al. Cooperative deformation of mineral and collagen in bone at the nanoscale. Proc. Natl Acad. Sci. USA 103, 17741-17746 (2006).

52. Nyman, J. S., Ni, Q. W., Nicolella, D. P. \& Wang, X. D. Measurements of mobile and bound water by nuclear magnetic resonance correlate with mechanical properties of bone. Bone 42, 193-199 (2008).

53. Chaplin, M. Opinion - Do we underestimate the importance of water in cell biology? Nature Rev. Mol. Cell Biol. 7, 861-866 (2006).

54. Beshah, K., Rey, C., Glimcher, M. J., Schimizu, M. \& Griffin, R. G. Solid-state carbon-13 and proton NMR-studies of carbonate-containing calcium phoshates and enamel. J. Solid State Chem. 84, 71-81 (1990).

55. Babonneau, F., Bonhomme, C., Hayakawa, S. \& Osaka, A. Solid state NMR characterization of nano-crystalline hydroxy-carbonate apatite using 1H-31P-13C triple resonance experiments. Mater. Res. Soc. Symp. Proc. 984 MM06-05 (2006).

\section{Acknowledgements}

We thank IMM Recherche, especially L. Behr, for providing the fresh bone samples, S. Casale for HRTEM observations, A. Anglo and C. Illoul for preparation of bone thin sections for TEM observations, Ö. Sel and C. Boissière for insightful discussions and critical suggestions, A. Délice and C. Paquis for technical assistance, and E. Ruiz-Hitzky for giving us the opportunity to perform dynamic water sorption measurements at the Instituto de Ciencias de Materiales de Madrid (CSIC, Spain). This work was supported by the Agence Nationale de la Recherche (ANR) through the ANR-09-BLAN-0120-01 'NanoShap' program. The French Région Ile de France SESAME program is acknowledged for financial support (700 MHz spectrometer)

\section{Author contributions}

Y.W. and S.V.E. contributed equally to this work. Y.W., S.V.E., F.M.F., M.S., G.L., G.P-A., C.C., T.A. and N.N. performed the research; F.B. looked for financial support for the project; Y.W., S.V.E., F.M.F., S.C., M.S., G.L., L.B., M-M.G-G., F.B., T.A. and N.N. analysed data; S.V.E., F.M.F., S.C., T.A. and N.N. wrote the paper; F.M.F., S.C., T.A. and N.N. designed the research; T.A. and N.N. wrote the project and supervised the work.

\section{Additional information}

Supplementary information is available in the online version of the paper. Reprints and permissions information is available online at www.nature.com/reprints. Correspondence and requests for materials should be addressed to T.A. or N.N.

\section{Competing financial interests}

The authors declare no competing financial interests. 
a

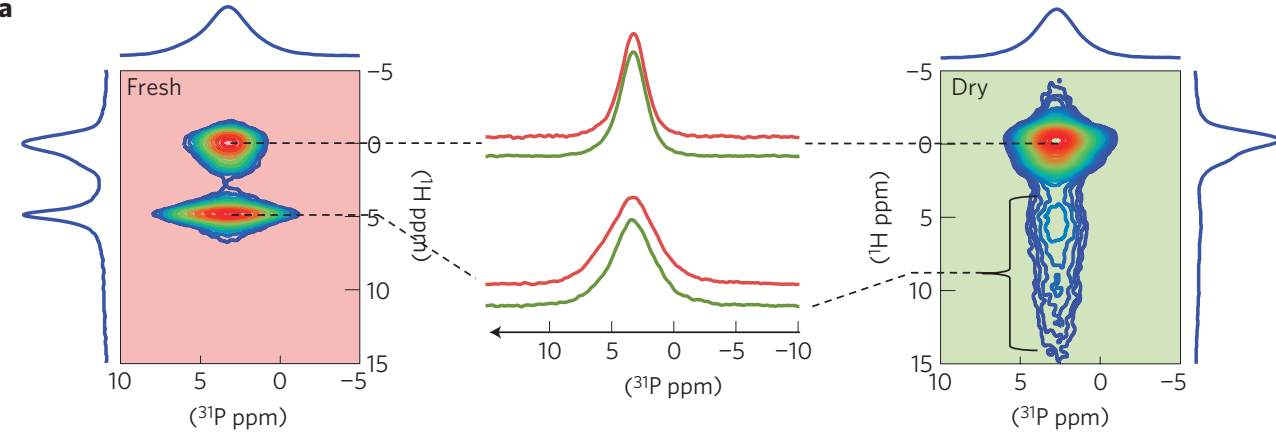

b
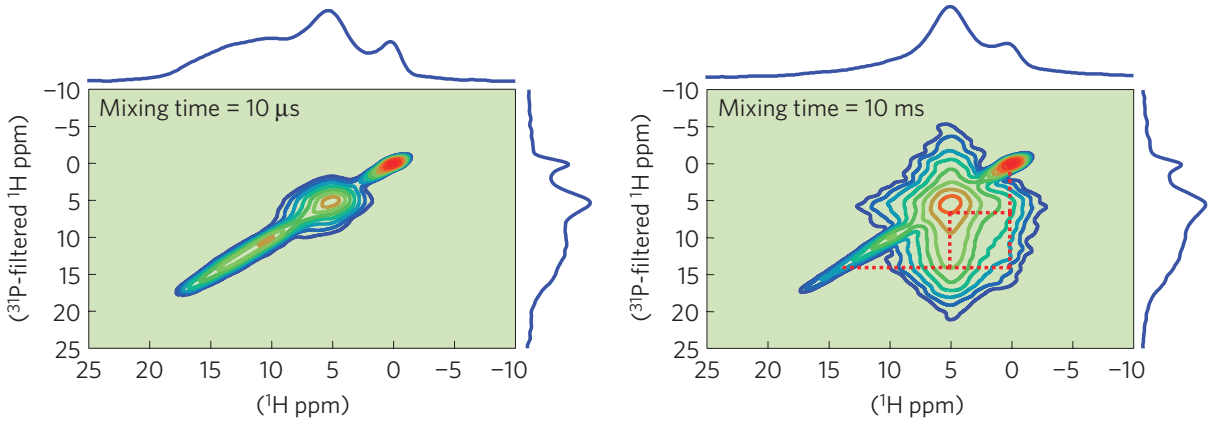

C

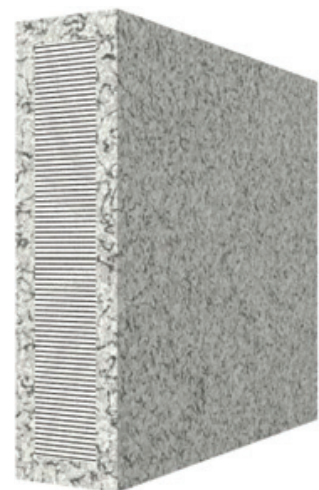

d

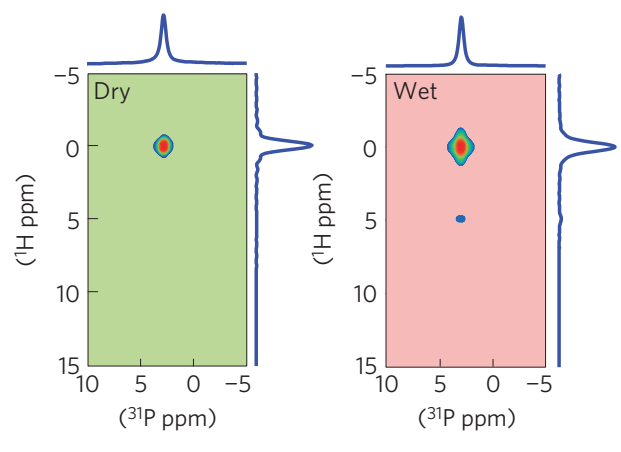

Figure 1 | The ability of bone apatite particles to adsorb water molecules at their surface is mediated by a hydrophilic surface layer. $\mathrm{a}, 2 \mathrm{D}{ }^{1} \mathrm{H}-{ }^{31} \mathrm{P}$ HetCor experiments recorded on fresh intact (red) and dry (green) sheep bone (contact time CT=10 ms) reveal two phosphate environments in bone. Only phosphates located at the surface of bone mineral are sensitive to a hydration/dehydration process. According to the respective extracted ${ }^{31} \mathrm{P}$ slices, the two correlation peaks detected for the fresh bone correspond to phosphates from the apatitic core $\left(\delta\left({ }^{1} \mathrm{H}\right)=0\right.$ ppm) and from the hydrophilic surface $\left(\delta\left({ }^{1} \mathrm{H}\right)=4.85 \mathrm{ppm}\right)$. Although their chemical shifts are $\operatorname{similar}\left(\delta\left({ }^{31} \mathrm{P}\right)=3.2 \mathrm{ppm}\right)$, the broader linewidth of this latter resonance $\left(\mathrm{LW}\left({ }^{31} \mathrm{P}\right)=5.6\right.$ versus $2.2 \mathrm{ppm}$ ) is characteristic of phosphates in the outer hydrophilic domain of apatite platelets. $\mathbf{b}, 2 \mathrm{D}^{31} \mathrm{P}$-filtered ${ }^{1} \mathrm{H}-{ }^{1} \mathrm{H}$ EXSY spectra (mixing time $=10 \mu \mathrm{S}$ and $10 \mathrm{~ms}$ ) of bone. After proton magnetization exchange, the correlations observed between $\mathrm{OH}^{-}$, residual water and $\mathrm{HPO}_{4}{ }^{2-}$ resonances (red dashed line) provide evidence that the crystalline core and the surface mineral layer are present in the same nanocrystal. c, Schematic representation of bone apatite particles composed of an apatitic and a hydrophilic surface layer ( 55 versus $45 \%$ of volume fraction, respectively, as determined from the fitting of the ${ }^{31}$ P MAS spectrum of the bone sample; Supplementary Fig. 1b). d, The adsorption of water molecules at the apatite surface is not observed in the absence of the outer hydrophilic mineral layer as shown by $2 \mathrm{D}^{1} \mathrm{H}-{ }^{31} \mathrm{P}$ HetCor experiments recorded on wet (red) and dry (green) HCA nanoparticles $(\mathrm{CT}=1 \mathrm{~ms})$. The $2 \mathrm{D}$ spectra exhibit neither the adsorbed-water resonance $\left(\delta\left({ }^{1} \mathrm{H}\right)=4.85 \mathrm{ppm}\right)$ nor the ${ }^{1} \mathrm{H}$ broad resonance in the $5-15 \mathrm{ppm}$ range characteristic of this surface layer, but only the $\mathrm{OH}^{-} / \mathrm{PO}_{4}{ }^{3-}$ correlation that is characteristic of the apatitic core. 


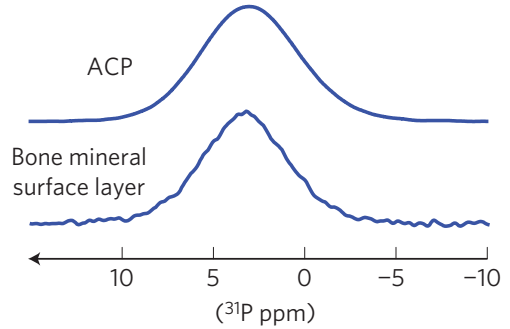

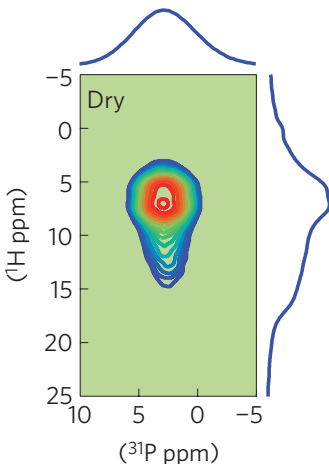

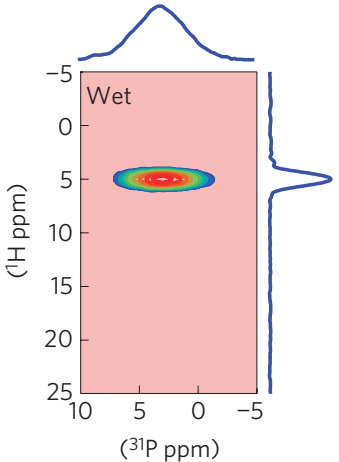

Figure 2 | The behaviour of the disordered surface layer of bone and biomimetic apatite is similar to that of an amorphous calcium phosphate phase on hydration/dehydration. $\mathbf{a}$, The ${ }^{31} \mathrm{P}$ cross-polarization MAS spectrum of $\mathrm{ACP}(\mathrm{CT}=2 \mathrm{~ms})$ presents similar features $\left(\delta\left({ }^{31} \mathrm{P}\right)=3.2 \mathrm{ppm}\right.$ and $\left.\mathrm{LW}=6.1 \mathrm{ppm}\right)$ compared to the ${ }^{31} \mathrm{P}$ resonance relative to the surface layer of bone mineral (spectrum extracted from the 2D HetCor spectra in Fig. 1a). $\mathbf{b}$, The spectroscopic behaviour of ACP on hydration/dehydration is also similar as shown by the $2 \mathrm{D}^{1} \mathrm{H}-{ }^{31} \mathrm{P}$ HetCor spectra of dry (green) and wet (red) ACP. The broad ${ }^{1} \mathrm{H}$ correlation signal ranging from 5 to $15 \mathrm{ppm}$ is entirely modified on complete hydration and merges into the characteristic single sharp peak $\left(\delta\left({ }^{1} \mathrm{H}\right)=4.85 \mathrm{ppm}\right)$.

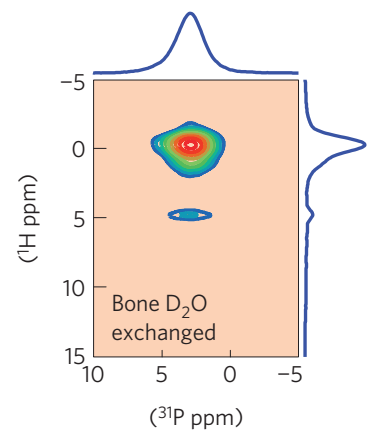

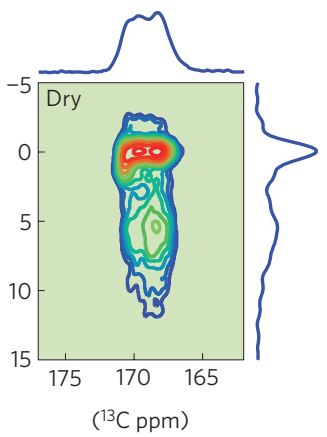

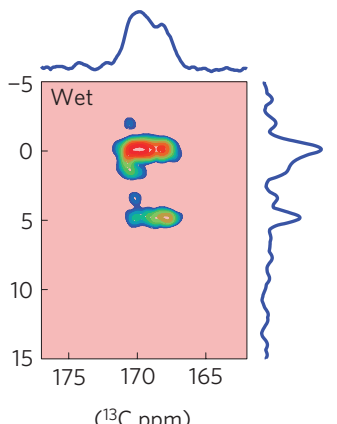

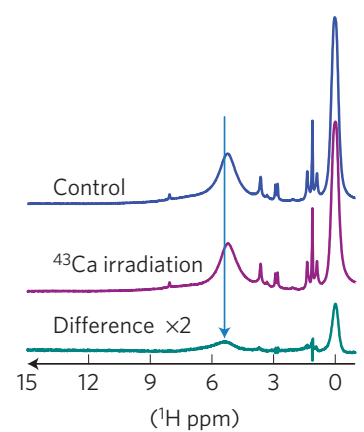

Figure 3 | Chemical composition of the ACP-like layer in apatites. a, After addition of $\mathrm{D}_{2} \mathrm{O}$ to the fresh bone sample, neither the sharp and strong proton water signal nor the weak and broad proton resonance characteristic of dry bone samples is detected through $2 \mathrm{D}^{1} \mathrm{H}-{ }^{31} \mathrm{P}$ HetCor spectroscopy $(C T=10 \mathrm{~ms})$. This indicates that water molecules are involved in a proton chemical exchange with mineral surface species, and confirms their nature as $\mathrm{HPO}_{4}{ }^{2-}$ ions and residual $\mathrm{H}_{2} \mathrm{O}$. b. The presence of a substantial number of $\mathrm{CO}_{3}{ }^{2-}$ ions in this layer is demonstrated by $2 \mathrm{D}^{1} \mathrm{H}-{ }^{13} \mathrm{C}$ HetCor experiments $\left(\mathrm{CT}=1 \mathrm{~ms}\right.$ ) realized on ${ }^{13} \mathrm{C}$-labelled $\mathrm{CHA}$ samples (biomimetic apatite). For the dry powder, the carbonate ions from the apatitic core, mainly in $\mathrm{A} / \mathrm{B}$ type $\left(\delta\left({ }^{13} \mathrm{C}\right)=168.3\right.$ and $\left.169.6 \mathrm{ppm}\right)$ and $\mathrm{B}$-type $\left(\delta\left({ }^{13} \mathrm{C}\right)=170.5 \mathrm{ppm}\right)$ substitution, are signing with hydroxyl ions $\left(\delta\left({ }^{1} \mathrm{H}\right)=0 \mathrm{ppm} ;\right.$ refs 27,54$)$. The weaker resonance at $\delta\left({ }^{1} \mathrm{H}\right)=1.3 \mathrm{ppm}$ is characteristic of a $\mathrm{OH}^{-}$close to B-type carbonates ${ }^{55}$. When soaked in water, the broad proton correlation resonance characteristic of $\mathrm{HPO}_{4}{ }^{2-}$ /residual water in the dry state (green) merges into the typical single resonance at 4.85 ppm that correlates with the carbonates from the disordered layer (maximum at $\delta\left({ }^{13} \mathrm{C}\right)=167.8 \mathrm{ppm}$ ) (red). c, The presence of $\mathrm{Ca}^{2+}$ in the disordered layer is demonstrated by a ${ }^{1} \mathrm{H}-\left\{{ }^{43} \mathrm{Ca}\right\}$ TRAPDOR experiment recorded on a ${ }^{43} \mathrm{Ca}$-labelled $\mathrm{CHA}$ sample. Besides the strong dephasing of the 0 ppm signal corresponding to hydroxyls in the apatitic core, the dephasing of $5.2 \mathrm{ppm}$ resonance (arrow) provides evidence of the presence of residual water near calcium atoms. 

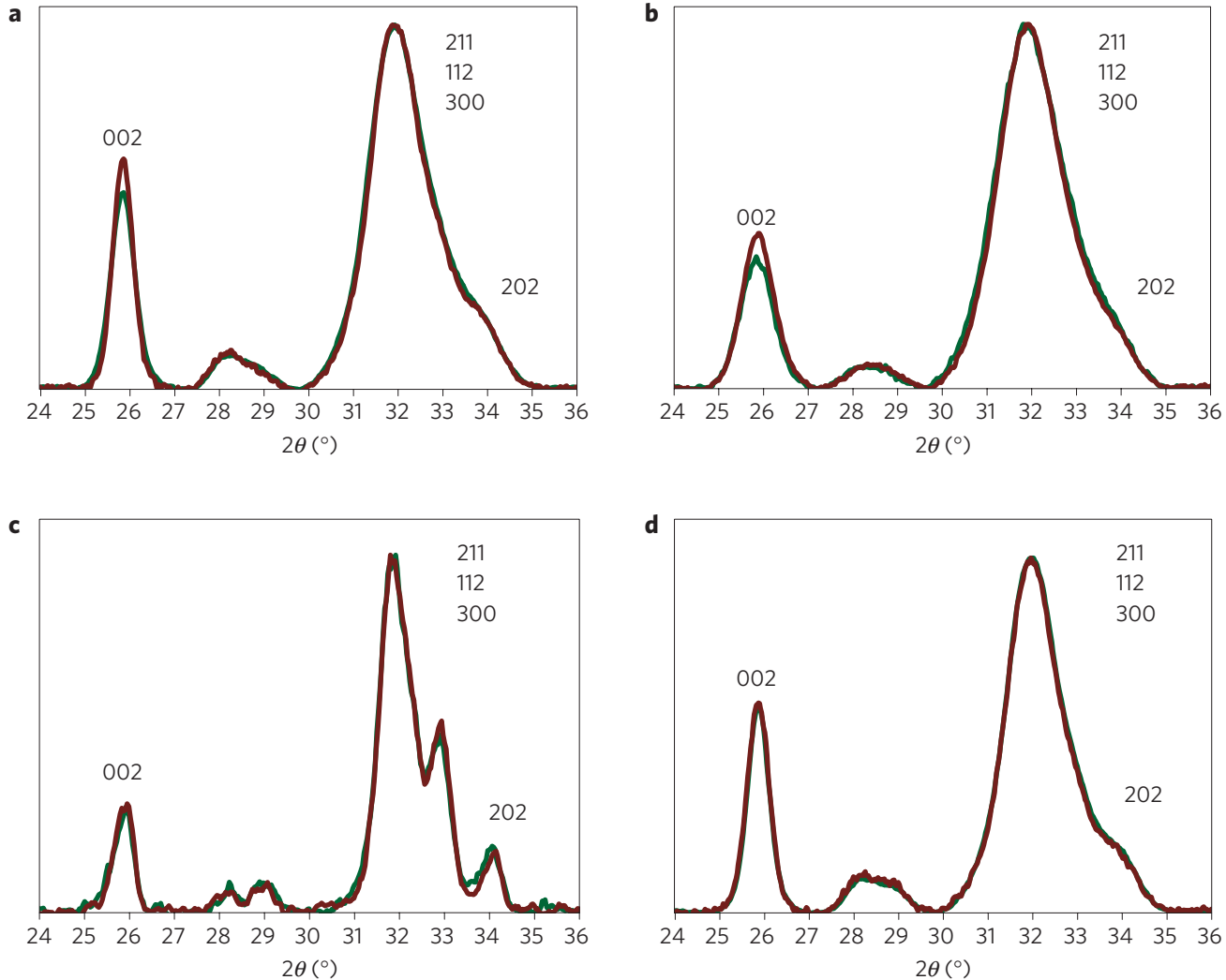

Figure 4 | Orientation of biomimetic HA platelets. a-d, 1D radial average of the WAXS patterns for dry (green) and $\mathrm{H}_{2} \mathrm{O}$ wet (red) $\mathrm{CHA}$ (a), $\mathrm{CHA}-\mathrm{SBF}$ (b), HCA (c) and CHA-200 (d) powders. 

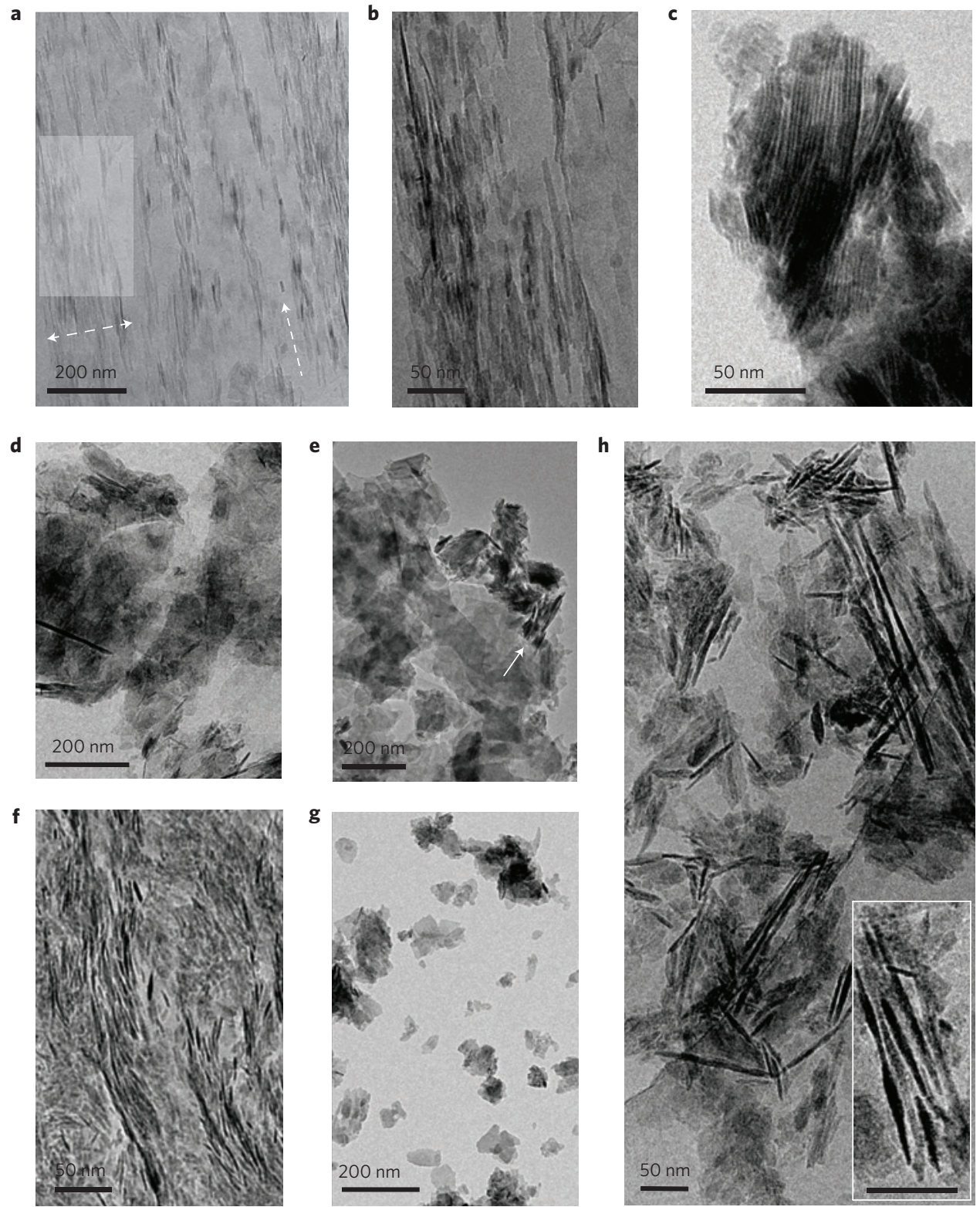

Figure 5 | Bone and biomimetic apatites can organize locally in the presence of water. a-e, Observations of synthetic mineral particles: cryoTEM pictures of the CHA sample at low (a) and higher magnification (b). The rectangle in $\mathbf{a}$ indicates the enlarged section that is shown in $\mathbf{b}$. The single- and double-headed dashed arrows in a indicate a longitudinal and lateral packing of the platelets, respectively, in agreement with the diffraction data. c,d, CryoTEM pictures of the monodispersed CHA-SBF particles show that they are locally more regularly packed (c), whereas CHA-200 particles exhibit a random distribution (d). Aggregates are rarely observed. This emphasizes the need for an ACP layer for the oriented stacking. e, TEM picture of CHA dispersed in water shows mainly a random distribution of the particles but also a few aggregates (white arrow). $\mathbf{f}-\mathbf{h}$, Observations of bone mineral particles. f, Thin-section TEM micrograph of unstained embedded fresh sheep bone showing the alignment of apatite crystals inside the organic matrix. $\mathbf{g}$, Standard TEM picture of extracted bone particles dispersed in ethanol showing a random distribution of the inorganic particles as previously reported in the literature ${ }^{44}$. In contrast, the cryoTEM picture of extracted bone particles (inset, scale bar $50 \mathrm{~nm}$ ) reveals that the behaviour of the biological apatite particles is similar to that of the biomimetic ones $(\mathbf{h})$. 


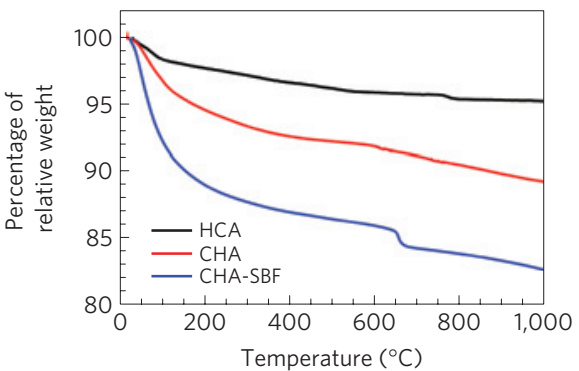

C

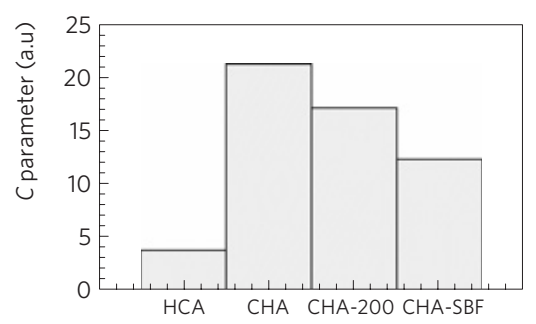

d

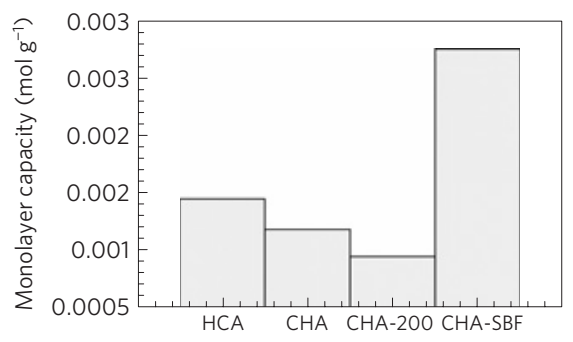

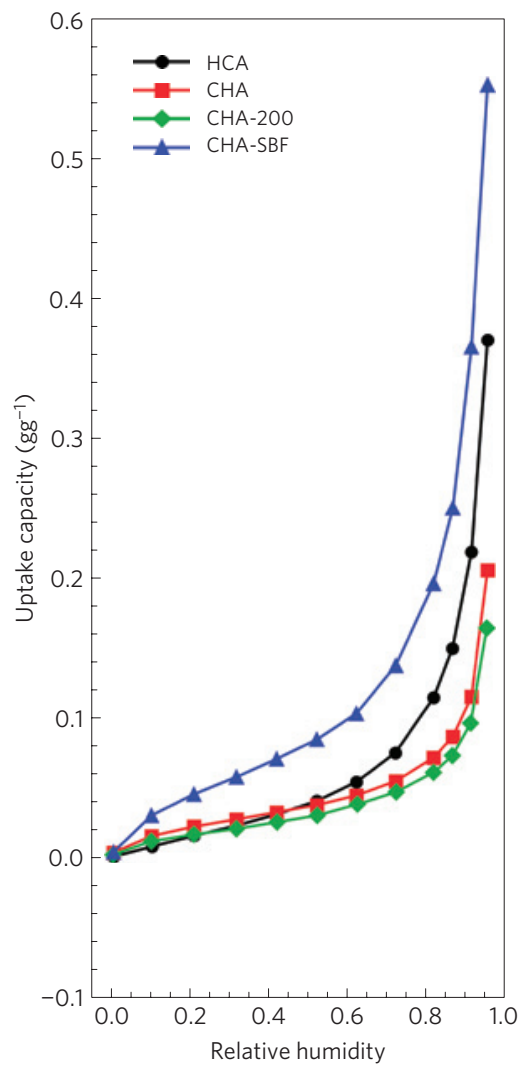

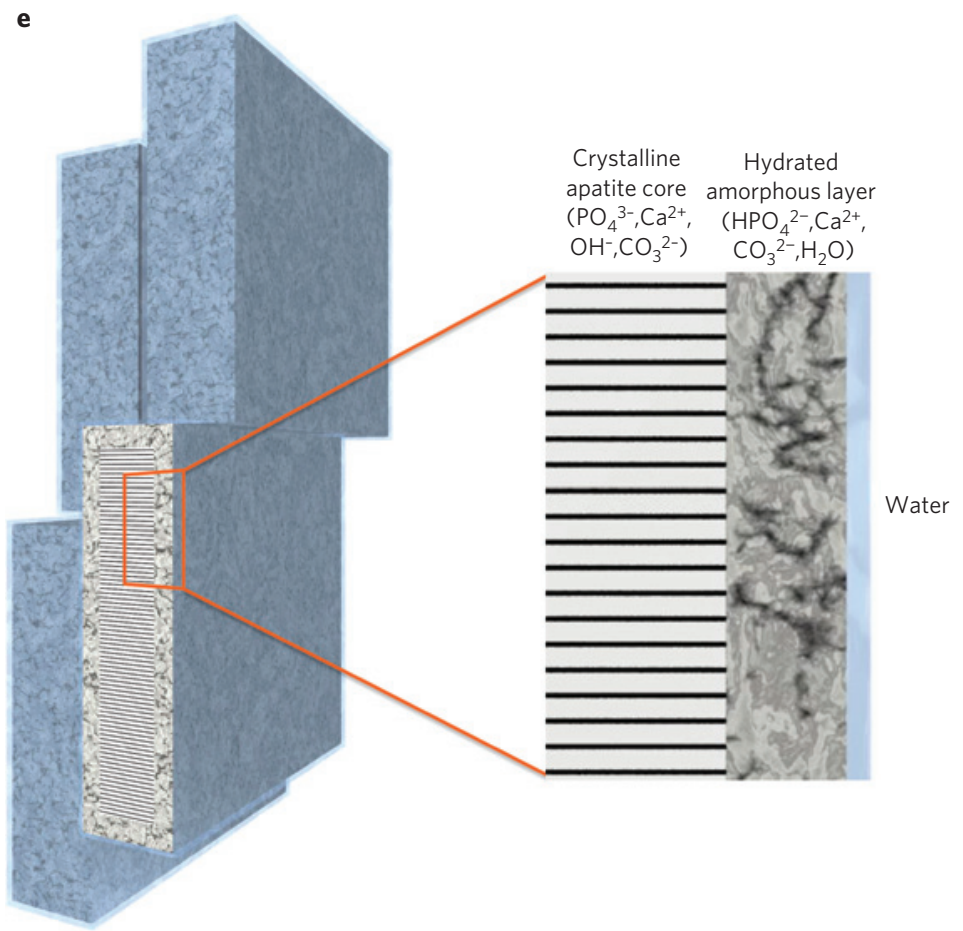

Figure 6 | The extension of the apatite/water interface depends on the presence of a disordered layer. a, Thermogravimetric analysis of apatite samples conditioned in ambient conditions reveals the differences in water retention (measured below $400^{\circ} \mathrm{C}$ ) presented by the different samples. $\mathbf{b}$, Water dynamic sorption isotherms performed between 0 and $95 \%$ relative humidity show how differently the apatite samples capture water at $60^{\circ} \mathrm{C}$. $\mathbf{c}, \mathbf{d}$, Fitting the adsorption isotherms obtained at $37^{\circ} \mathrm{C}$ to the Brunauer-Emmett-Teller model allows drawing information regarding the energy between the first water monolayer and the apatite surface (c) as well as the extension of the monolayer (d) in thermodynamic conditions close to those observed in vivo. e, Schematic representation of the stacking of apatite platelets. The platelets are composed of a crystalline apatitic core and an amorphous layer composed of $\left(\mathrm{PO}_{4}{ }^{3-}, \mathrm{Ca}^{2+}, \mathrm{OH}^{-}, \mathrm{CO}_{3}{ }^{2-}\right)$ and $\left(\mathrm{HPO}_{4}{ }^{2-}, \mathrm{Ca}^{2+}, \mathrm{CO}_{3}{ }^{2-}, \mathrm{H}_{2} \mathrm{O}\right)$, respectively. Water molecules that form a structuring network with the hydrated ACP-like layer induce the orientation of the HA platelets. 